\title{
11 Experiences and Lessons from Conducting an Emergency Survey of Motorists During the UK Fuel Crisis \\ GLENN LYONS AND MARK BEECROFT
}

\section{Introduction}

The transport research community is no stranger to conducting studies of travel behaviour. It has at its disposal a range of methodologies with which to gather behavioural data for analysis. Some approaches involve the study of ongoing 'normal' behaviour to gain insight into how and why people's daily routines, travel patterns and travel preferences and perceptions are formulated. Other approaches seek to create experimental environments to which individuals can be exposed in order to gather feedback on their reactions in such environments. Those environments might be artificial by exposing individuals to hypothetical situations. Stated preference techniques are a commonly used approach for this whereby individuals are asked to respond to a series of hypothetical choices (Ortúzar and Willumsen, 1998).

Alternatively, experimentation can intervene in real life. For example, May et al. (1998) studied drivers' responses to a range of road user charging (RUC) regimes. Participants from Newcastle University staff were provided with suitably equipped vehicles and a float of real money to use to go about their everyday lives with a hypothetical RUC scheme in place. This forced them to consider trade-offs between saving time on their daily journeys through making payments and saving the money they had been given. In Hampshire four companies took part in a teleworking trial in which employees were exposed for the first time to this way of working (Lyons, 1998). Travel diaries, questionnaires and interviews were used to acquire feedback from the participants. Such experimental arrangements typically afford the researchers substantial control over the experimental set 
up. The experiment often has a clearly defined start and end point and it is common for two (or more) stages of feedback to be gathered from those taking part. The first stage assesses circumstance, attitudes and behaviour before the experiment is initiated. The second stage assesses comparable issues after the experiment is initiated. A subsequent stage may assess such issues again once the experimental environment has been removed. Such studies, by virtue of their detailed nature, can be expensive to set up and typically involve a comparatively small number of individuals.

The September 2000 fuel crisis in the UK inadvertently created conditions that were comparable to an experimental environment on a national scale involving huge numbers of participants. The 'experiment' involved the effective rationing of the supply of fuel to car users thereby rendering car use a finite resource. In these circumstances people were forced to confront their car dependence. They were required to review and appraise their daily routines and travel patterns and use of alternatives to the car.

It would have been impossible to intentionally create by design and then control the conditions encountered during the fuel crisis in the form of an experiment. There was no advance notice provided that the 'experiment' was taking place. Nevertheless the fuel crisis created an unprecedented opportunity to gather data that might yield fresh insight into car dependence.

This chapter presents and discusses the experiences of one group of researchers that undertook to monitor and evaluate the 'experiment'. The Transportation Research Group (TRG) at the University of Southampton conducted a survey of car users in the immediate wake of the fuel crisis to capture the experiences of individuals during the crisis in terms of its impacts on daily routines and travel. The process followed was not altogether untypical of a personal travel survey. However, the defining characteristic of this particular study was the time frame. Although the fuel crisis had no clearly defined beginning or end, the week commencing Monday 11 September 2001 in essence constituted the period of the fuel crisis. On Thursday 14 September the TRG made a decision to conduct a survey. By Friday 22 September (thanks to a major teamwork exercise) it had distributed 5000 mailback questionnaires. Colleagues elsewhere in England (in West Yorkshire (Leeds, Bradford, Wakefield, Kirklees, Calderdale), Leicester, Hertford and the London Borough of Hillingdon) distributed approximately a further 6000 questionnaires.

The chapter highlights the obstacles, opportunities and challenges faced in pursuing the survey. It also reflects on issues that contributed to its eventual success and those that served to compromise the survey's achievements. The validity and implications of referring to the fuel crisis 
as an experiment are considered further. The extent to which the research community might have been better prepared to seize this opportunity and how it might take preparatory steps now to capitalise on future opportunities is explored. The findings of the survey have been presented in Chapter 7 (Chatterjee and Lyons, 2002). Chapter 14 (Bonsall, 2002) will extend the discussion concerning what can be learned from crises.

At the end of this chapter the first author's diary of events is included. This provides a chronological account of the work undertaken in carrying out the survey. It also seeks to convey the pressures faced, the multitude of tasks to be completed and the importance of teamwork in the course of the survey process.

\section{Survey Design}

\section{Survey Instrument}

The principal aim of the survey was to understand how and why choices concerning trips and activities had been affected by the fuel crisis. To understand how trips and activities are affected by a change in circumstance a travel and/or activity diary is often an appropriate survey instrument to use. It allows an individual or household to document a chronological account of their routine over a number of days. However, with no advance notice there was no possibility of using travel diaries to record people's routines before the crisis to allow comparison with their routines during the crisis. In addition it was considered too late by the time of the week following the fuel crisis to expect individuals to retrospectively complete a diary for the previous week. A common concern with the use of diaries is that of underreporting of trips or activities by participants - diary surveys demand a lot of time of respondents (Kalfs and Saris, 1997). This consideration would have been an even greater concern in a retrospective context.

Key to selecting and designing an appropriate survey instrument for the fuel crisis was the need to act quickly to gather information from the public before their memories faded or became distorted. In acknowledgement of the retrospective nature of the survey, a lack of a complete and precise recollection of events and detail was considered inevitable. Therefore it was decided that rather than trying to acquire details of all individual trips made and activities undertaken by survey respondents, it was more appropriate to detect types of changes to routine and choices that took place and the incidence of such changes across respondents. 
Three options for the survey instrument then existed, namely: (i) telephone interviews; (ii) face-to-face questionnaire interviews; and (iii) self-completion mailback questionnaires. Options (i) and (ii) faced three main limitations:

- The inability to record detailed accounts from respondents: These survey instruments are more amenable to closed questions with tickbox responses. In addition, oral surveys and telephone interviews in particular have been found to 'produce relatively poor results in terms of trip reporting in comparison with written surveys (e.g. mail-back travel surveys)' (Hassounah et al, 1993).

- The need for trained personnel to conduct the interviewing: The short timescales of the survey precluded either outsourcing the interviewing to a specialist agency or obtaining and then training a sufficient number of internal staff to perform the task.

- The need to acquire a sufficient number of responses: The unique nature and scale of the crisis suggested an inherent value in securing feedback from as many people as possible to harness the potential diversity of circumstance and behaviour faced during the crisis. These survey instruments would not have allowed large numbers of responses to be acquired within the time and resource available.

Option (iii) provided a greater flexibility in terms of question design and would allow a potentially greater number of individuals to respond with detailed accounts of their experiences and reactions. This option was therefore adopted.

\section{Questionnaire Design}

The final version of the resulting questionnaire is included at the end of the chapter. The main content of the questionnaire centred on four journey types: the journey to/from work; journeys made whilst at work; escorting children to/from school or pre-school; and grocery shopping. To avoid an excessive questionnaire length it would not have been feasible to explicitly consider more than four journey types. The types selected reflect a substantial proportion of travel undertaken in the UK. For 1997/99, the National Travel Survey identified that 'commuting', 'business', 'escort education' and 'shopping' journeys accounted for 54 per cent of all journeys made as car/van drivers and 33 per cent made as car/van passengers (DETR, 2000). A section of the questionnaire was devoted to each journey type with a common format for each section. (Other sections concerned personal details of the respondent, other changes to household 
routine and travel and the respondent's views about the fuel crisis.) Closed questions were asked to determine how each journey type is 'normally' undertaken. Respondents were then asked to describe in their own words any changes to their 'normal' practice that occurred during the fuel crisis week and how good or bad experience of the change was. Questions were also asked to ascertain whether such alternative approaches had been adopted previously or would be considered again beyond the crisis. Reference to 'normal' was for practical purposes in the questionnaire design. It is acknowledged that 'normal' for many people may not represent single, repetitive behaviour - they may have a lot of 'normal' variability in terms of the timing, location and mode of access for activities. In other circumstances a travel or activity diary would have been effective in capturing this variability.

Designing the questionnaire in this way raised some concerns. Firstly, the questionnaire would need to accommodate a range of different types of respondents facing different circumstances. For example, the patterns of activity and travel of retired people are likely to be substantially different to those of young, single, working people which will be different again to those of couples with young children. Using the same questionnaire for all sectors of the population of interest introduces elements of redundancy and irrelevance into the questionnaire design and restricts the opportunity for more targeted, relevant questions. In other circumstances it would have been appropriate to use an initial set of screening questions to stratify respondents. Each respondent could then have been provided subsequently with a variant of the general questionnaire designed more specifically for the corresponding stratum. Time constraints did not allow for this option.

A second concern related to the resulting length of the all-purpose questionnaire design. With its coverage of issues and requirement for free text responses to many questions it posed a risk of taking too long to complete. There was concern that this could have an adverse effect on the response rate for the survey. A calculated risk was taken. It was assumed that the length of time to complete the questionnaire would be offset by the high level of public interest in the fuel crisis and a wish amongst many to share their views and experiences by responding to the questionnaire. An additional financial incentive in the form of entry into a cash prize draw was also included. A reduced questionnaire length would have diminished the richness of the dataset emerging from the survey. In the event this judgement appears to have been reasonable - survey response rates are discussed later.

A major consequence of having many free-text response questions was the substantial time required subsequently to firstly transcribe the 
questionnaire responses and secondly process the responses and categorise them to allow quantitative analysis to proceed.

\section{Piloting}

For any questionnaire survey there is a need to ensure that the survey design, and in particular the questionnaire content, will work with those to whom the questionnaire is directed and will yield the data required. To do this requires pilot work whereby survey design is tested and refined ordinarily this can be a lengthy process (Oppenheim, 1998). A questionnaire survey conducted without pilot work runs a serious risk of at least partial failure in terms of questions being misunderstood by respondents, key questions being omitted or response rate being very low because of the overall questionnaire design or means of distribution. When conducting an emergency survey no time is afforded for thorough pilot work. This places considerable pressure on those designing the survey. A limited attempt was made to pilot the draft questionnaire via some 10-12 friends, family and neighbours of TRG staff.

\section{Questionnaire Distribution}

It was determined at an early stage that the population of interest for the survey would be car drivers as opposed to the general public at large. A more precise definition of the population of interest that was targeted in practice was car users (thereby encompassing some individuals who do not drive but who, as passengers, depend to some extent upon the use of a car). The survey was not designed with the intention of learning how those who do not use a car were affected by the crisis. This is not to say that they were not affected - overcrowding on public transport services as patronage levels swelled may well have caused disruption or inconvenience to non car users. Indeed Thorpe et al. (2002) found that, during the crisis, some individuals switched from public transport to car use perhaps because of a deterioration in the level of service on public transport and more free flowing roads due to reduced traffic levels.

One option for distributing mailback questionnaires was to use the postal service to deliver questionnaires to households in specified post code areas. However, this had two distinct disadvantages. Postal distribution introduces a wastage given the inability to target only households with individuals within the population of interest (i.e. car users). Using the postal service for distribution would have taken a number of days to arrange, causing unacceptable delay. Further to this, the postal service 
itself was suffering at the hands of the crisis. Five alternative forms of distribution were actually utilised:

- Fuel stations. With the crisis itself over and tankers replenishing fuel stocks on forecourts, fuel stations seemed to provide a natural distribution point. The majority of individuals visiting fuel stations are, by implication, car drivers or users (notwithstanding the increasing attempt by many stations to also act as local supermarkets). At the point of visiting a fuel station, refuelling and the issue of the crisis were likely to have been uppermost in people's minds. A number of fuel stations agreed to have questionnaires placed on their forecourts.

- Primary schools. Primary school children by implication are in households with young families and most, if not all, will involve parents in escorting the children to school. A number of schools agreed to send a questionnaire home with each child for their parents. Whilst this would not necessarily have only targeted the population of interest it ensured that the survey data would have school escort trip information well represented, subject to a good response rate. This form of distribution, as with that above, also minimised the manpower requirements of distribution imposed on the research team.

- City and town centres. City and town centres provide a means to target a broader cross section of the public, an opportunity to target distribution at the population of interest and a greater likelihood of targeting individuals who will complete the questionnaire given the voluntary nature of receiving a questionnaire. Within this form of distribution, car parks and shopping areas were targeted. This form of distribution required a number of staff to support it. Depending on the exact point of distribution this can also be more susceptible to weather conditions (which were not altogether favourable during the survey) than other methods.

- Door-to-door. Door-to-door distribution is equivalent to the postal service option discussed earlier, i.e. questionnaires are delivered to households without ascertaining either whether the household contains individuals within the population of interest or whether such individuals are prepared to complete a questionnaire. Due to unfavourable weather conditions that limited the rate of distribution onstreet, door-to-door distribution was used as a supplementary measure and targeted at villages.

- Electronic distribution. In addition to the distribution of the mailback questionnaire, a duplicate version of the questionnaire was created for the web. This allowed individuals with access to the Internet from any physical location in the UK to participate in the survey. A key 
determinant of success for this form of distribution is the degree of awareness of its existence amongst the population of interest. This is discussed later in this chapter.

The TRG is based in Southampton. For mailback questionnaire distribution in the forms described above, the geographical coverage of the survey was limited to Hampshire and South Wiltshire. There was concern that such a limitation would substantially impinge upon the extent to which the survey response sample would be representative of the UK, or England, as a whole. The Internet proved an invaluable aid to addressing this problem, separate to its use for the web-based questionnaire. The chapter authors share in the operation of an e-mail discussion list for young transport professionals. A request was made to list members from across the UK for support in questionnaire distribution. A number of colleagues agreed to help in various parts of England as indicated in Figure 11.1 below. The questionnaire was produced using Microsoft Word. Therefore it was possible to email the document to colleagues. They in turn produced sufficient paper copies for their own distribution needs (in the case of Leicester the Word questionnaire document was distributed electronically with respondents either completing and returning it electronically or printing it out for completion and returning it by post).

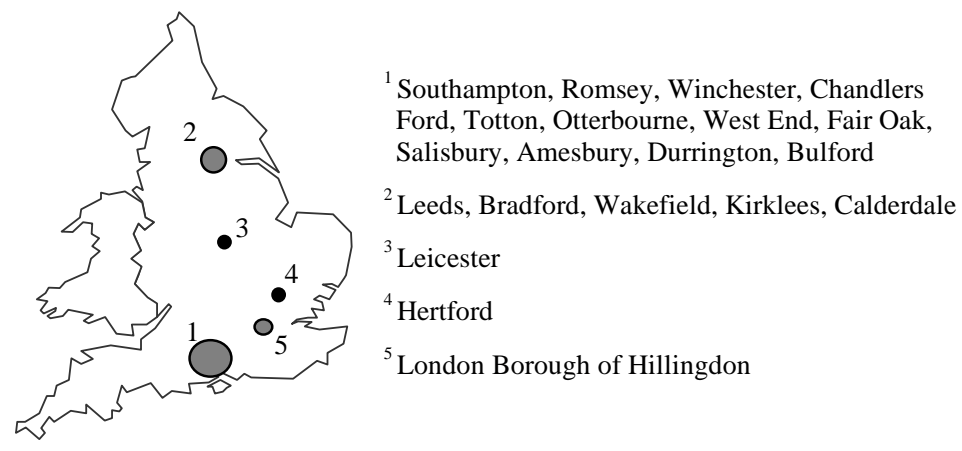

Figure 11.1 Areas of distribution for the mailback questionnaire

Without the Internet it would not have been possible to expand the geographical coverage in this way. Nevertheless, under the tight time constraints for the survey, the research team at Southampton was unable to record survey distribution information for areas 2-5 to the same level of detail as for area 1 (available details concerning areas 2-5 are included at the end of this chapter ${ }^{1}$ ). For areas 2-5 an area identifier only was stamped 
on each questionnaire distributed. For area 1, each questionnaire was stamped with a unique ID number. The specific location and method of distribution was logged for nearly all ID numbers.

\section{Response Rates}

Table 11.1 shows the estimated response levels and rates attained according to the distribution methods employed for area 1. Table 11.2 shows the response rates for the five survey areas.

In terms of the four principal means of distributing the mailback questionnaires the highest response rate was from petrol stations (average response rate approximately 25 per cent), followed by town/city centres (22 per cent), house to house (20 per cent) and primary schools (19 per cent). The comparative response rates are intuitively sensible. For petrol stations and town/city centres, all individuals have 'volunteered' to take a questionnaire whereas for primary schools and house to house individuals receive a questionnaire regardless. What is perhaps more surprising however is that the response rates for 'volunteers' are not substantially greater than for others and yet town/city centre distribution was much more resource intensive. This might provide a lesson for any future 'crisis' survey where time and resources are at a premium. Nevertheless, response rates are clearly not in themselves a measure of the success of the survey.

The response rate for area 1 is noticeably higher than for the other areas as shown in Table 11.2. There are two probable reasons for this. Firstly, the figures for how many questionnaires were distributed in areas other than area 1 are approximate and represent maximum values. Many of these questionnaires may have been despatched for distribution without actually being taken by prospective respondents. Secondly, as described below, the survey was well publicised in area 1 whereas in other areas publicity was limited or nil. 
232 Transport Lessons from the Fuel Tax Protests of 2000

Table 11.1 Comparison of response rates across distribution methods for area 1

Location Distribution
means $\quad$ Distribution Responses $\begin{array}{r}\text { Response } \\ \text { rate (\%) }\end{array}$

\begin{tabular}{|c|c|c|c|c|}
\hline Durrington $^{3}$ & Primary & 145 & 36 & 24.8 \\
\hline Chandlers Ford $^{9}$ & school (infant & $200^{\mathrm{a}}$ & 41 & 20.5 \\
\hline Winchester $^{5}$ & and/or junior) & $204^{\mathrm{b}}$ & - & - \\
\hline West End ${ }^{10}$ & & 132 & 27 & 20.5 \\
\hline Romsey $^{6}$ & & 226 & 28 & 12.4 \\
\hline Bulford $^{3}$ & House to & 170 & 30 & 17.6 \\
\hline Durrington $^{3}$ & house & 144 & 34 & 23.6 \\
\hline Otterbourne ${ }^{11}$ & & 20 & 3 & 15.0 \\
\hline Chandlers Ford $^{9}$ & & 200 & 46 & 23.0 \\
\hline Fair Oak ${ }^{8}$ & & 100 & 13 & 13.0 \\
\hline Amesbury $^{2}$ & Town or city & 105 & 25 & 23.8 \\
\hline Salisbury $^{1}$ & centre & 105 & 22 & 21.0 \\
\hline Southampton ${ }^{4}$ & & 600 & 89 & 14.8 \\
\hline Romsey $^{6}$ & & 726 & 181 & 24.9 \\
\hline Winchester $^{5}$ & & $600^{c}$ & 143 & 23.8 \\
\hline Durrington $^{3}$ & Petrol station & 110 & 34 & 30.1 \\
\hline Romsey $^{6}$ & & 288 & 80 & 27.8 \\
\hline Totton $^{7}$ & & $300^{\mathrm{a}, \mathrm{d}}$ & 35 & 11.7 \\
\hline Winchester $^{5}$ & & 208 & 51 & 24.5 \\
\hline Durrington $^{3}$ & $\begin{array}{l}\text { Rangers } \\
\text { petrol station } \\
\text { - account } \\
\text { holders }\end{array}$ & 100 & 19 & 19.0 \\
\hline Southampton ${ }^{4}$ & $\begin{array}{l}\text { University } \\
\text { staff club }\end{array}$ & 61 & 19 & 31.1 \\
\hline Winchester $^{5}$ & $\begin{array}{l}\text { Alternative } \\
\text { transport day } \\
\text { stall }\end{array}$ & 136 & 37 & 27.2 \\
\hline Winchester ${ }^{5}$ & Email/web ${ }^{\mathrm{e}}$ & lown & 21 & nown \\
\hline
\end{tabular}


Experiences and Lessons from Conducting an Emergency Survey 233

\section{Table 11.1 Comparison of response rates across distribution methods} for area 1

$\begin{array}{ccc}\text { Location } \begin{array}{c}\text { Distribution } \\ \text { means }\end{array} & \text { Distribution Responses } & \begin{array}{r}\text { Response } \\ \text { rate (\%) }\end{array}\end{array}$

$\begin{array}{lllll}\text { Amesbury }^{2} & \text { Health } & 20^{\mathrm{a}} & 4 & 20.0 \\ & \text { Centre / } & & \\ & \text { Doctor's } & & \\ & \text { surgery } & & \end{array}$

1 Salisbury is a Cathedral City in Wiltshire with a population of approximately 40,000

2 Amesbury is a small town in Wiltshire 8 miles north of Salisbury with a population of approximately 6,000

3 Durrington and Bulford are villages in Wiltshire 1 and 2 miles from Amesbury respectively

4 Southampton is a City in Hampshire with a population of approximately 220,000

5 Winchester is a Cathedral City in Hampshire with a population of approximately 35,000

6 Romsey is a town in Hampshire 8 miles north-west of Southampton with a population of approximately 13,000

7 Totton is a town in Hampshire 4 miles west of Southampton with a population of approximately 28,000

8 Fair Oak is a village in Hampshire 8 miles north-east of Soutampton

9 Chandlers Ford is a village in Hampshire 6 miles north of Southampton and adjacent to the town of Eastleigh

10 West End is a village in Hampshire three miles east of Southampton

11 Otterbourne is a village in Hampshire 9 miles north of Southampton and adjacent to the town of Eastleigh

a Not all questionnaires made available for the public may have been taken/distributed - the response rate is therefore a minimum estimate b No responses at all were received from this batch - it is assumed therefore that they were not distributed

c Approximately 50 of this batch were distributed house to house

d No responses from the latter 100 assumed to be distributed were received - it assumed that these were not therefore distributed

e The questionnaire as an electronic Word document was emailed around an organisation in Winchester

Table 11.2 Comparison of response rates by survey distribution area

Distribution area

1 - Hampshire/Wiltshire

2 - West Yorkshire

3 - Leicester

4 - Hertford

5 - Hillingdon

unknown

All areas*
Distributed

Returned

Response rate (\%)

$\begin{array}{rrr}4596 & 1018 & 22 \\ 5000 & 416 & 8 \\ \mathrm{n} / \mathrm{a} & 77 & \mathrm{n} / \mathrm{a} \\ 760 & 70 & 9 \\ 500 & 52 & 10 \\ \mathrm{n} / \mathrm{a} & 26 & \mathrm{n} / \mathrm{a} \\ 10856 & 1659 & 15\end{array}$

* Distribution values for areas 2, 4 and 5 are approximate and n/a cells are treated as zero values - hence values for all areas are approximate 
234 Transport Lessons from the Fuel Tax Protests of 2000

\section{The Web as a Questionnaire Medium}

The UK has a population of nearly 60 million (Office for National Statistics, 2001). Estimates of the number of people in the UK with Internet access vary and the actual figure is continually growing. At around the time of the fuel crisis one source put the number of people in the UK using the Internet every month from home at 11 million in September 2000 (Jupiter MMXI, 2000). In addition to home users there are others who have access at home but do not make use of it and others who use the Internet at work. In other words a substantial proportion of the UK population would have been able to access a questionnaire placed on the web. This represented an opportunity to potentially harness questionnaire responses from literally thousands of people across the UK at very little cost.

A web questionnaire is essentially an on-line form. An individual accesses the questionnaire using a web browser and completes it electronically using the computer keyboard and mouse. Finally an onscreen button is clicked to submit the response electronically back to the computer hosting the web questionnaire. Responses are automatically stored in a database removing the requirement for transcription.

However, one factor is decisive in the effectiveness of a web questionnaire - individuals must be aware of the existence of the questionnaire and easily be able to locate it if they are to become survey respondents. Therefore, for the web version of the fuel crisis survey (identical to the mailback questionnaire) it was essential to promote its existence. Promotion was pursued using a variety of means:

- messages sent to email discussion lists (with encouragement for such messages to be forwarded to others in a chain letter style);

- requests to and offers from other web site operators to place links to the questionnaire on their web sites; and

- $\quad$ radio and press coverage.

At a local level (the Southampton area) all these means of promotion were achieved. Regrettably, at a national level attempts to gain radio and press coverage failed. A prime time evening slot was secured for a promotional interview on BBC Radio 2 on Wednesday $20^{\text {th }}$ September. However, minutes before the broadcast the show's producer withdrew the opportunity because of fears triggered by another radio station (Cardiff based Red Dragon FM) that the fuel crisis was recommencing (BBC, 2000). It will never be known how many responses could have been generated from this crucial promotional opportunity. Nevertheless, over 700 responses were received for the web questionnaire during the 12-day 
period for which it was made available. Figure 11.2 shows the number of daily responses received. It also highlights the points at which different forms of publicity became effective.

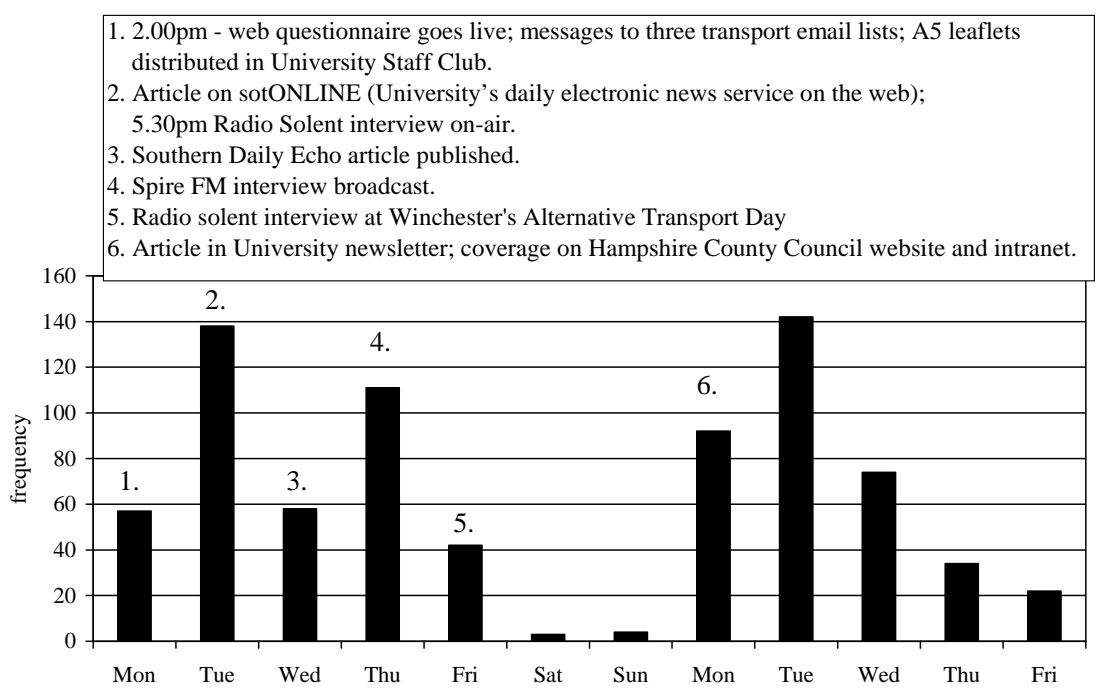

Figure 11.2 Daily responses to the web questionnaire between Monday $18^{\text {th }}$ September and Friday $29^{\text {th }}$ September 2000 and corresponding known instances of promotion

In addition to the questionnaire completion, web survey respondents were asked to indicate how they had learned of the web survey. From responses to this open question it is clear that the most effective means of promotion was email. Approximately half of the respondents had learned of the web survey from receiving an email message. From indications of the means of promotion attracting respondents, the chain letter style of promotion did indeed take place. The original promotional email messages posted to discussion lists by the TRG were forwarded to a number of other discussion lists, circulated within organisations and passed around between friends and colleagues. On the second Monday and Tuesday 234 responses were received. Of these, 53 per cent arose as a direct result of promotion item 6 shown in Figure 11.2. Promotion item 6 represents promotion within the workplace and in this case involved organisations with widespread Internet access amongst their staff. Local radio and newspaper articles only achieved a minor effect in terms of successful promotion. 
These observations highlight the effectiveness of the 'electronic grapevine' in promoting a web survey. There are two suggestions regarding the cause of this. Firstly, there was almost universal interest in the topic of the survey across the UK and a consequent willingness and enthusiasm for people to pass on promotion of the survey. This would be unlikely to exist in ordinary circumstances for a web survey. Secondly, this form of promotion is likely, in most cases, to have been received in the workplace environment and, by implication, received in most cases by individuals sat at a computer with immediate access the web and hence the web survey. The promotion therefore has the possibility to achieve immediate effect in contrast to radio and newspaper promotion. In the case of the latter the individual would typically have been required to note down the web address of the survey to follow up at a later time - with the initial stimulus of the promotion perhaps diminished. The success of electronic propagation of promotion might also be attributed to its more narrowcast (transmission to a specified list of recipients) nature as opposed to the broadcast (transmission to multiple, unspecified recipients) nature of radio and newspaper. Most instances of forwarding the email promoting the web survey would have involved the sender believing that the message would be of interest to the individual or group being targeted.

Given the forms of promotion that proved most effective for this web survey, respondents are likely to have been mostly professional, in contrast to the mailback survey which captured a broader cross-section of the population. Hence response bias issues must be addressed. Chapter 7 focuses on the mailback survey responses. The analysis of the web survey is not included in this book. It will be reported elsewhere in due course along with a comparison of the two sets of responses.

There is a growing experience within research communities of using the Internet for conducting surveys (e.g. Polak et al., 1999). As populations become increasingly familiar with and able to use the Internet then it is likely to become an increasingly valuable survey instrument. This is particularly the case where large numbers of people (possibly in disparate locations) are affected by a common event or crisis which may be short lived. A cluster of unannounced crises hit the UK in the winter of 2000/2001. Following the fuel crisis, a major rail crash resulted in a huge infrastructure programme causing serious disruption to passenger train services. Flooding affected large parts of the UK and foot and mouth returned to the UK for the first time since 1967. Each of these in different ways (whilst none of them were as short lived as the fuel crisis) provided opportunities to learn more about human behaviour in a climate of intense media interest capturing national attention - fruitful territory for the use of an Internet survey. 


\section{Funding Research in a Crisis}

A substantial proportion of academic research in the UK is funded by research councils. A typical process to gain funding for a research proposal from the Engineering and Physical Sciences Research Council (EPSRC) is as follows. A research proposal is submitted to the EPSRC and sent for review to individuals with recognised expertise in the field. This can take several weeks. If reviewers' feedback is favourable then either: (i) funding may be awarded if the value of the proposal is small; or (ii) the proposal joins a number of others that are taken forward to a Panel meeting which may take place some further weeks hence. In the case of the latter, proposals are ranked and a funding 'cut-off' identified which determines which projects will be funded and taken forward. To varying degrees all research sponsors follow similar procedures of assessment that usually preclude any immediate decision on a request for funding.

For the fuel crisis it was considered vital that the survey commenced without any delay. The TRG therefore took the unusual step of choosing to underwrite the cost of conducting the survey in case funding from elsewhere could not be secured subsequently. This enabled the survey work to be commenced without delay. Three working days into the survey a short proposal for funding was prepared and submitted to the EPSRC. The EPSRC demonstrated commendable flexibility and haste in its response. Upon receipt of the proposal to cover the costs of the survey, EPSRC was able to agree to fund the work within the space of just over two weeks having sought and received comments from three referees and avoided passing the case to a Panel meeting. The TRG then, having completed the survey itself, submitted a follow-on proposal to the EPSRC for funding to conduct the data entry, analysis and reporting for the survey. This proposal was refereed in the normal way and awarded funding.

This approach to securing funds for the work proved highly effective. It enabled the time critical nature of the survey work itself to be addressed to capture the research data. It was then possible in a more measured way to take stock of the outcome of the survey and the number of responses and to consider a suitable approach for establishing and disseminating research findings from the collected data. However, the success of the survey relied upon the research group itself undertaking to commence the work with no guarantee of funding. To wait even the two weeks for approval from EPSRC would have seriously compromised the outcome of the work undertaken. 
238 Transport Lessons from the Fuel Tax Protests of 2000

\section{Teamwork}

Success of the survey was crucially dependent upon the large number of individuals within and associated with the TRG and those in other parts of the UK who contributed to the work. As a reminder, in the space of five working days the TRG team, from scratch: initiated the project; designed, tested and revised a mailback and web questionnaire; distributed 5000 copies of the mailback questionnaire; and achieved publicity for the web questionnaire drawing over 360 responses in its first four days of existence. A multitude of tasks was involved alongside the survey design including: the mundane process of preparing copies of ID stamped questionnaires with mailback envelopes and preparing laminated posters for use by the questionnaire distributors; technical matters associated with the web questionnaire; publicity efforts; recruitment of temporary staff; and distribution coordination.

The TRG is comprised of some 35 staff and postgraduate research students. The majority of these took a role, great or small, in the survey. In addition, friends and family were drafted in to provide temporary support. This short-lived and intense project arose with no prior notice. No staff had the opportunity to forward plan in order to accommodate their contribution to the fuel crisis survey alongside their other work commitments. Business as usual in the group still had to continue. It is therefore a credit to all those concerned how effectively a large team of people worked together to achieve the goals of the project.

\section{An Experimental Environment?}

Earlier in this chapter the fuel crisis was referred to as a national 'experiment'. In many regards this description is fitting although it is prone to be misleading. Referring to the fuel crisis in this way wrongly implies a degree of experimental control. In interpreting the results of any experiment and judging what the implications might be, it is important to ensure that there is no ambiguity with regard to how the experimental results have arisen and what they represent.

It would be wrong to suppose that for all the fuel crisis survey respondents, the same degree of fuel rationing applied or that the fuel crisis began and ended at the same time for all respondents. In practice different parts of the UK suffered varying levels of fuel shortages at different times. Across the population some individuals secured ample fuel for their immediate requirements whilst others had little or none. The population as a whole could not be aware of the length of the crisis until it had concluded. 
Therefore conduct across individuals is likely to have varied depending upon perceptions of likely duration as well as the changing degree of fuel availability. This highlights the added complications faced, over and above a more conventional experiment or survey, in conducting and interpreting the analysis of the data obtained.

It is impossible to resolve precisely how such considerations impinge upon the validity of the survey findings or their interpretations. In many ways this is true of any experiment. Crises hold the prospect of rich rewards in terms of the effects they can have on behaviour if monitored but such rewards come at the price of the caveats that must surround the results. Such matters for this particular survey are considered in greater detail in Chapter 7 and more broadly in Chapter 14.

\section{Preparing to Monitor and Evaluate Behaviour in a Future Crisis}

The fuel crisis survey met with a surprising degree of success given the constraints and pressures that it faced. In some respects it merely demanded a well-oiled execution of all the stages and principles of good practice in conducting any travel behaviour survey. In other respects it has exposed some of the unique challenges and opportunities that a national crisis can bring for a survey that seeks to assess its impacts. It might be argued that there is little to be gained in devising a contingency plan for monitoring and evaluating behaviour in a future crisis. Each crisis will possess its own unique characteristics. In spite of the spate of crises that has recently beset the UK, crises remain an exception rather than a norm. However, crises can represent tremendous research opportunities when they occur. They can create conditions akin to experimental environments on a large scale that behavioural researchers could only dream of creating themselves. It therefore seems appropriate that this chapter should conclude with contemplation of a contingency plan, or at least some points of discussion regarding one.

Funding is a dilemma if external sponsors are to be approached. A decision for the study of a crisis to go ahead may be required in a matter of days or even hours rather than the weeks or months typically required. A sponsor might have in place an allocation of emergency funds to support a crisis study. However, to release such funds it would not be sufficient to be persuaded of the merits of an opportunity presented. The research team would still need to be judged as credible to carry out the work. For these reasons it is suggested that the model that was followed for the fuel crisis survey is an appropriate one. It should be the internal responsibility of a research team to be prepared to initially meet the costs of a crisis study. If 
the team is confident of its value then it should be confident of recovering its costs from a sponsoring body. Sponsoring bodies should be encouraged to have in place a mechanism to deal with such a situation if they do not already do so.

This chapter has highlighted the pressures that survey design can be placed under. Time is of the essence and a multitude of decisions and tasks must be addressed. Under pressure it can be easy for such matters to be addressed in a sequential fashion rather than in parallel. Thinking in parallel affords at least a few hours or days of advance planning for matters such as pilot work. In the case of this survey, only limited pilot work was possible because of no advanced planning. Ultimately a crisis survey faces the limit of the number of available person hours that can be devoted to the work. However, the availability, at the work commencement, of a checklist for all decisions and tasks can enable a project plan to be drawn up and the critical path of activities to be identified. This is normal project management procedure, but can be easily overlooked or inadequately addressed in crisis conditions.

Survey design should consider the extent to which the crisis in question can be defined in terms of experimental design. Thinking in this way can expose some of the uncontrolled factors that are at play. Whilst control cannot be imposed, questions can be posed that will minimise the risk of ambiguity or inability to interpret the findings from the experiment.

Teamwork was instrumental in the success of the fuel crisis survey. To carry out the work successful not only required sufficient people but an ability to match tasks and decisions to individuals' abilities and expertise. For a future crisis survey this would principally include those within the organisation pursuing the crisis survey. However, prompt identification of other individuals and contact details for matters such as issue of press releases, obtaining police permission for on-street survey distribution, recruitment of temporary staff and mass production of questionnaire material is also important. It may be advantageous for more than one research organisation to join forces to address a crisis survey. This will require an even more thorough appreciation of the roles of different team members. It is suggested that either within a research organisation or within a research community a crisis task force be identified which can be mobilised when required. This might consist of a number of individuals and their corresponding skills identified for inclusion in a potential crisis survey research team. More likely is that it would consist of one or more identified individuals who possess the knowledge and organisation skills to advise on or take a direct role in the management of a crisis survey.

There is still much to learn about the use of the Internet to conduct surveys (particularly in terms of the self-selection of respondents and the 
associated bias in responses) but it is a medium that is increasingly familiar to growing proportions of national populations. As discussed earlier in this chapter its principal advantage is being able to make a questionnaire widely available in a very short space of time when only limited survey resources are present. For the fuel crisis survey the Internet questionnaire was considered a supplementary means of gathering information to the main mailback survey. It is suggested that for a future crisis a reversal of this priority might be considered (particularly at such a time when Internet access becomes sufficiently widespread to ensure a representation of the entire population in survey responses). The public increasingly look to the Internet to find and exchange information. A survey should be conducted in a way that takes advantage of this. For example, during the Foot and Mouth crisis it is estimated that nearly 500,000 Britons visited the Ministry of Agriculture, Food and Fisheries website in March 2001 seeking information (Jupiter MMXI, 2001). Imagine the potential promotional opportunity a link on this website would have presented for a crisis survey.

A crisis survey is not something to be undertaken lightly. It is extremely demanding. One moves quickly from observing or being part of the crisis itself to being part of a newly created crisis - namely the research crisis. The plus side is the prospect of securing a valued contribution to knowledge that would otherwise have been lost forever.

\section{Acknowledgements}

Sincere thanks are due to all those individuals who kindly helped in this venture. They include: members of the TRG and their partners and friends; Reg Harman (Independent Consultant and Visiting Senior Research Fellow with the TRG); Andy Salkeld (Leicester City Council); Jeanette Sargent (West Yorkshire Passenger Transport Executive); Mark Silverman (London Borough of Hillingdon); and Paul Chu (Mott MacDonald). There are numerous others, many of whom we are not even aware, not least those who shared in the propagation of the web survey promotion and those who considered our request for funding. To everyone concerned we owe a debt of thanks.

\section{Notes}

1 Known details concerning forms of distribution in areas 2, 4 and 5 are as follows. Area 2: approximately 3,000 distributed through local councils, to local councils' staff and community Groups in Leeds, Bradford, Calderdale, Kirklees and Wakefield (proportions of 'public' and 'internal' distribution are not known); and an additional 2,000 
242 Transport Lessons from the Fuel Tax Protests of 2000

questionnaires were distributed in city centre car parks in Leeds. Area 4: 600 to Simon Balle Comprehensive School in Hertford, 100 in Gravesons Department Store in Hertford and the Tourist Information Centre, 60 directly by hand. Area 5: 400-500 distributed at petrol stations, libraries, housing department and voluntary user groups (approximately 100 each).

\section{References}

BBC News Online. Website. Careless talk costs litres. Available at: http://newsvote.bbc.co.uk/low/english/uk/wales/newsid_933000/933405.stm [accessed 04/09/01]

Bonsall, P. (2002). What can be Learned by Studying Transport Crises? In Lyons, G. and Chatterjee, K. (eds.) Transport Lessons from the Fuel Tax Protests of 2000, Ashgate, Aldershot.

Chatterjee, K. and Lyons, G. (2002). Travel Behaviour of Car Users During the UK Fuel Crisis and Insights into Car Dependence. In Lyons, G. and Chatterjee, K. (eds.) Transport Lessons from the Fuel Tax Protests of 2000, Ashgate, Aldershot.

DETR (2000). Transport Statistics Great Britain: 2000 Edition. Department of the Environment, Transport and the Regions, London, TSO.

Hassounah, M.I., Cheah, L.-S. and Steuart, G.N. (1997). Underreporting of trips in telephone interview travel surveys. Transportation Research Record 1412, TRB, 90-94.

Jupiter MMXI (2000). 11 million people in the UK now use the Internet every month. Press release, November. Available at: http://uk.jupitermmxi.com/press/releases/ 20001114.jsp. [accessed 03/09/01].

Jupiter MMXI (2001). Britons turn to the Internet in a crisis. Press release, April. Available at: http://uk.jupitermmxi.com/press/releases/20010417.jsp. [accessed 03/09/01].

Kalfs, N. and Saris, W.E. (1997). New data collection methods in travel surveys. In: Ettema, D.F. and Timmermans, H.J.P. (eds) Activity-Based Approaches to Travel Analysis, Pergamon.

Lyons, G.D. (1998). An assessment of teleworking as a practice for travel demand management. Transport, 129(4), ICE, 195-200.

May, A.D., Bonsall, P.W. and Hills, P.J. (1998). Evaluation of driver response to road user charging systems. Proc. $9^{\text {th }}$ International Conference on Road Transport Information and Control, April, London, IEE, 30-34.

Office for National Statistics (2001). Mid-2000 UK population estimates, August, National Statistics, London.

Oppenheim, A.N. (1998). Questionnaire Design, Interviewing and Attitude Measurement. Pinter.

Ortúzar, J. de D. and Willumsen, L.G. (1998). Modelling Transport. Wiley.

Polak, J., Plaxton, J., Jackson, P.G. and Wofinden, D. (1999). Using the Internet to improve long-distance travel data collection. Transportation Research Record 1660, TRB, 148155.

Thorpe N., Bell, M., Polak J. and Noland R. (2002). A Telephone Survey of Stated Travel Responses to Fuel Shortages. In Lyons, G. and Chatterjee, K. (eds.) Transport Lessons from the Fuel Tax Protests of 2000, Ashgate, Aldershot. 


\section{DAY 1 - Thursday $14^{\text {th }}$ September 2000}

At home - teleworking to conserve fuel. My wife has walked the children to school. On Tuesday I suggested to an email discussion list that the fuel crisis was an opportunity to understand how people react when they have to compromise their car dependence. This would be a research opportunity if not for the short notice and the problem of funding.

Had a telephone conversation with Professor McDonald, our Group Director, to discuss any possibilities for pursuing such research. We agreed the Transportation Research Group itself would underwrite the costs of an 'emergency' survey in the absence of an immediate source of funds.

Late today there were signs from media reports that the immediate problems of the fuel crisis - the blockade of refineries and distribution centres - might be about to end. A survey to capture the effects of the crisis will need to be conducted as soon as possible. A mailback questionnaire will be the best option - this will need to be ready for distribution early next week. I called Mark Beecroft at the office and we agreed to assume joint responsibility for completing the survey. Mark has suggested a TRG brainstorm meeting first thing tomorrow.

I started thinking through concepts and ideas for the questionnaire and discussed them with my wife as a prospective respondent. I also drew up an action list for tomorrow. Mark, meanwhile, plans to ring round family and friends to get insights into how the crisis has been affecting them. 


\section{DAY 2 - Friday $15^{\text {th }}$ September 2000}

At work just after 6am to continue with questionnaire design - focussing on a section for each main trip type which can identify typical travel arrangements and changes (if any) during the crisis. Copies of partially complete draft questionnaire given to those attending the brainstorm meeting.

Six staff attended the meeting. The main point of discussion was the detail of the survey instrument. We considered travel diaries, interview surveys and preliminary screening surveys but time constraints necessitated the more generalised mailback questionnaire approach. Open versus closed questions and the need to capture interdependencies between different trips and activities were discussed. It was agreed to target the survey at adult car users only. 3000 questionnaires was estimated as a target for distribution. I undertook to complete a draft of the questionnaire by the end of the day. Meanwhile Mark, with support from three other staff, set about preparing 3000 A5 envelopes with FREEPOST address labels.

With concern over geographical coverage, Mark and I contacted a number of colleagues in other parts of the UK who agreed to help by undertaking their own distribution of the questionnaires. Notably, Jeanette Sargent of the West Yorkshire Passenger Transport Executive undertook to make some enquiries with the relevant local authorities in and around Leeds.

EPSRC contacted me about other matters. We discussed what the TRG was doing and they suggested if I could get a proposal for funding to them immediately they could turn it around very promptly subject to a favourable responses from referees (a similar exercise had been completed in response to an earthquake when researchers had needed funds to travel to the zone to collect data/information). I explained that there was simply not time at this stage to prepare a proposal and complete the survey design.

I spent the rest of the day designing the questionnaire. Once it was completed it was emailed to all those in different parts of England who were interested in taking part in the distribution. As a substitute for piloting the survey, five members of staff agreed to take home copies of the draft questionnaire to test on a limited number of people. At home this evening I spent several hours preparing an HTML version of the questionnaire to be posted on the TRG website. 


\section{DAYS 3 and $4-$ Saturday $16^{\text {th }}$ and Sunday $17^{\text {th }}$ September 2000}

I spoke with a local petrol station proprietor who agreed to distribute the questionnaire. The station has a typical footfall of 1000 people a day. It was anticipated that on Monday and Tuesday the garage would be very busy as fuel supplies arrived. With an estimate of 1 in 8 people taking a questionnaire over three days up to 500 questionnaires would be required for this point of distribution alone. Working on the basis of targeting perhaps three petrol stations and three schools as well as city centre distribution, it became clear that 3000 was an inadequate estimate of total distribution. I decided to revise the total to 5000 and prepared a detailed action list for Monday to ensure the survey could continue to plan.

Late Saturday evening I sent an email to the Radio 2 'Drive Time' show in the hope they would be interested in covering the survey.

My wife and her friend began making plans to distribute the questionnaire on Tuesday and Wednesday in Salisbury and Amesbury.

My wife, one of my neighbours and a family friend each completed the questionnaire and provided feedback. Work colleagues also emailed through feedback. I spent more of the weekend making notes on how to refine the questionnaire. 


\section{DAY 5 - Monday $18^{\text {th }}$ September 2000}

Arrived at work at 6.00am to begin revisions to the questionnaire. Following further emails received with feedback, the final version of the questionnaire was ready. A colleague did the proof reading and it was then dispatched at 9.30am for mass production.

Three research students were enlisted to help other TRG staff with preparation of more mailback envelopes and in turn putting the photocopied questionnaires together with envelopes. Each questionnaire was also stamped with a unique I.D. number. A colleague's wife joined the team and assumed responsibility for contacting schools and petrol stations to secure support for distribution.

The on-line web questionnaire was revised and two other TRG staff dealt with the technical tasks associated with setting up the questionnaire to allow on-line responses to be stored directly into a database without the need for transcription. After external testing the web questionnaire went live at $2.00 \mathrm{pm}$. I then posted email messages to three email announcement/discussion lists promoting the web questionnaire.

I wrote a press release that then required liaison with the University's Public Affairs department to establish a final version which they would release. Attempts to get a supporting quote from a leading transport organisation failed, with no-one available to comment. Later in the day the press release was issued and was also placed on the Latest News section of the University website. A TRG colleague tried unsuccessfully to generate interest from four major newspapers in covering the survey.

I then prepared A4 colour posters (which required lamination), name badges and letters for the staff, family and friends enlisted to distribute the questionnaires onstreet. With permission obtained, questionnaires and A5 promotional flyers for the web questionnaire were taken over to the University Staff Club. A cover letter to be attached to all the questionnaires being distributed at schools was written and mass produced. Meanwhile Mark contacted all the relevant police authorities for permission to distribute questionnaires.

I departed for home with sufficient questionnaires for the local infants school, petrol station and distribution in Salisbury the following day. Our TRG secretary also took sufficient questionnaires for distribution at her daughter's primary school.

Late that evening I checked my email only to discover two messages concerning failed attempts to submit the web questionnaire. I investigated and discovered the problem but was limited from home in being able to fully resolve it. I also found an email from BBC Radio 2 who had tried (too early) to access the questionnaire on the web -I sent an email indicating that it was now available. Finally I went onto the EPSRC website and obtained the relevant documents for submitting a research proposal. 


\section{DAY 6 - Tuesday $19^{\text {th }}$ September 2000}

Arrived at work at $6.30 \mathrm{am}$ and wrote a proposal to EPSRC for the costs to cover the survey which was then agreed with the Group Director and passed to our secretary for submission to EPSRC.

Colleagues fully resolved the problem with the web questionnaire.

Mark spent the day co-ordinating and taking part in the distribution of the questionnaires in Romsey, Winchester and Southampton. Distribution staff got caught up in the new wave of panic buying of fuel triggered by the Welsh radio station Red Dragon.

The University's Public Affairs Department called to say they were receiving enquiries concerning the press release. The Southern Daily Echo was prepared to drop another article in the following day's issue to accommodate a 600 word piece. I wrote an article and passed it to Public Affairs. Public Affairs sent over a photographer for which I had to ask a colleague go and buy some razors to allow me to have an emergency shave! Then did a recorded interview with South City FM. Further phone calls with Radio 2 secured a live prime time 5 minute slot at $6.15 \mathrm{pm}$ that evening. Radio Solent called and a live interview was arranged on Drive Time at 5.30pm, also that evening.

The interview with Radio Solent went well including the clear mention of the Website address. Radio 2 then telephoned to say that the show's host was uncomfortable about doing the interview in view of the resumption of (unnecessary) panic buying - this opportunity was lost.

Reports back from those distributing questionnaires indicated that rainy weather had not been helpful although interest in the survey was generally strong - in light of the temporary resumption of panic buying some drivers even wound their windows down and beckoned to distributors to give them copies of the questionnaire to complete. 


\section{DAY 7 - Wednesday $20^{\text {th }}$ September 2000}

The Southern Daily Echo article was published today

I was teleworking once again - no longer because of the fuel crisis but because of a work-related crisis caused by pursuing the survey - I am responsible for a major industry workshop in London tomorrow concerning traveller information and had to prepare for the day including a substantial presentation to open the event.

During the day contact was made with Salisbury's Spire FM and I conducted a telephone interview.

Mark continued with the substantial task of questionnaires distribution.

\section{ADDENDUM: Thursday $21^{\text {st }}-$ Monday $25^{\text {th }}$ September 2000}

On Thursday an abridged version of the Spire FM interview was broadcast hourly during the day but unfortunately without the web address included.

By the end of Thursday, the TRG team had distributed 5000 questionnaires.

Alongside the frenetic activity locally, colleagues in Leeds, Bradford, Wakefield, Kirklees, Calderdale, Leicester, Hertford and the London Borough of Hillingdon has been similarly engaged in the distribution of a further 5000-6000 questionnaires.

Alongside the organisation of distribution, Mark attempted to log the details of activities and to arrange payment of casual staff.

The Southern Daily Echo article yielded an invitation, which Mark accepted, to have a stand at the Winchester Alternative Transport Day, part of the European Car-Free Day campaign, on Friday. This also resulted in a radio interview with BBC Radio Solent within which the web address was promoted.

Mark contacted the University's internal publication 'Bulletin' to arrange promotion of the survey in the next issue. Contact was made with Hampshire County Council's on-line services to broadcast the survey over HantsWeb/Hantsnet. On Monday both of these forms of promotion came into being. 


\section{FUEL CRISIS SURVEY}

\section{HAVE YOUR SAY}

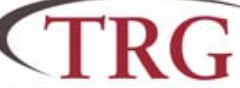

Transportation

Research Group

$+$

\section{Drivers' Survey}

How did you and your household cope last week and what changes did you make to your daily routine and journeys?

We hope this survey will help Government and other bodies take stock of how we use our cars and what this means for their policies.

Return this questionnaire by 29 September and you could win $£ 250$.

For this survey to be a success it is important that you try to remember as much as you can from the last week (week commencing Monday 11 September).

Queries? Telephone 02380592834 or email M.E.Beecroft@soton.ac.uk.

\section{SECTION 1 - ABOUT YOU}

Age (in years):

Sex (male/female):

Postcode:

Main occupation (please be as specific as possible)

Please list the details of all other people in your household:

\begin{tabular}{c|c|l|l|}
\hline Age & $\begin{array}{c}\text { Sex } \\
\text { (male/female) }\end{array}$ & Occupation Relationship to you \\
\hline & & & \\
\hline & & & \\
\hline & & & \\
\hline & & & \\
\hline & & & \\
\hline
\end{tabular}

Which of the following best describes where you live (please tick one only):
$\square$ remote area
$\square$ village
$\square$ town
$\square$ city (suburban)
$\square$ city (central/inner area)

How many cars or vans does your household have? (please include company owned vehicles)

Please describe the year, make, model and size of the vehicle you use the most for driving (e.g. 1993 Ford Escort 1.8 Diesel)

During a normal week how many miles do you drive using this vehicle? (please estimate to the nearest 10 miles):

How often do you normally refuel this vehicle (please tick only one):
$\square$ at least twice a week
$\square$ weekly
$\square$ fortnightly
$\square$ less than every two weeks

At the beginning of last week did you manage to refuel or already have at least half a tank of fuel in -

- your vehicle (yes/no)?

- other household vehicles (if applicable) (yes/no)?

Do you have access to a bicycle (yes/no)? 


\section{SECTION 2 - YOUR JOURNEY TO/FROM WORK}

If you do not work each day please go to Section 4.

Please give us details of how you USUALLY travel to/from work:

How do you get there (please tick more than one if, for example, your journey involves using a bus and a train):

$\square$ car - drive alone $\quad \square$ train $\quad \square$ work from home

$\square$ car-drive with passenger(s) $\square$ cycle $\square$ other (please describe)

$\square$ car - as passenger $\square$ walk

$\square$ bus $\square$ taxi

How many miles is it from your home to work?

How many minutes does it take to get from home to work?

What time do you arrive at work (to the nearest $1 / 4$ hour, e.g. $8.45 \mathrm{am}$ ):

If you did not change your journey to/from work (as you described above) on any of the days last week because of the fuel crisis please explain why below.

If you did change your journey to/from work on one or more days last week because of the fuel crisis please provide as much explanation of how below - we are interested in any changes to your usual journey to/from work as well as the affect these changes had on other journeys and aspects of your or your household's routine. Please indicate (if applicable) how good or bad you found this change of experience to your journey to/from work.

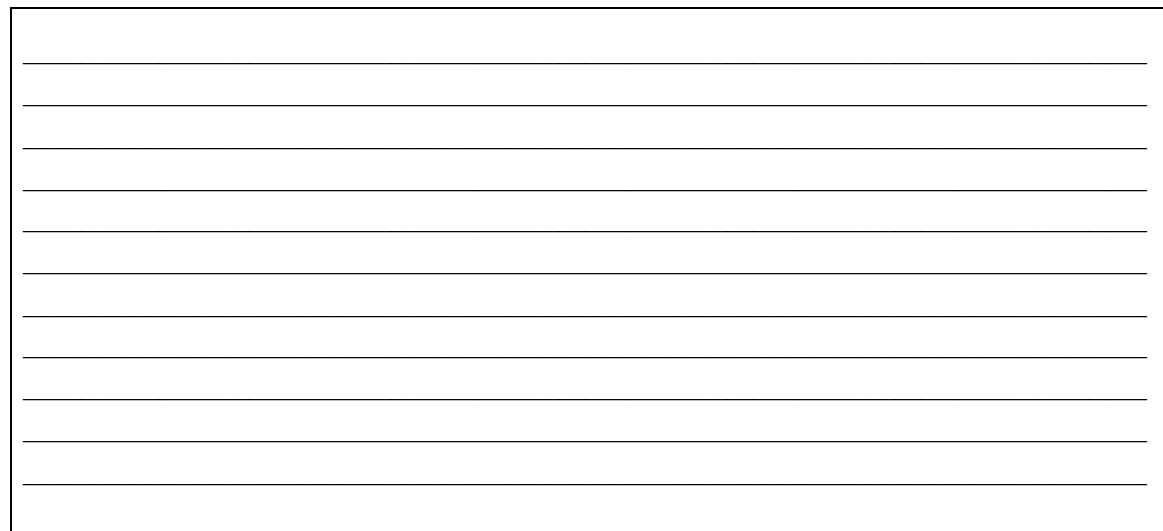

If you did change your journey to/from work:

Have you done so before in the last six months in the way you describe above (yes/no)?

Would you travel to/from work in this way again after the fuel crisis (yes/no)? (please explain why or why not below). 


\section{SECTION 3 - YOUR JOURNEYS MADE WHILE YOU ARE AT WORK}

If you do not work or do not make any journeys while you are at work please go to Section 4.

Please give us details of the journeys you USUALLY undertake for your work:

How often do you make long journeys at work, i.e. 5 miles or over (please tick one only):

$\square$ every day $\square$ at least twice a week $\square$ once a week $\square$ at least once a month $\square$ less than once a month

What form(s) of transport do you usually use for these journeys:

How often do you make short journeys at work, i.e. less than 5 miles (please tick one only):

$\square$ every day $\square$ at least twice a week $\square$ once a week $\square$ at least once a month $\square$ less than once a month

What forms(s) of transport do you usually use for these journeys:

What is the main purpose of these journeys (please describe)?:

If you did not make any changes to journeys undertaken at work on any of the days last week because of the fuel crisis please explain why below.

If you did make changes to journeys undertaken at work on one or more days last week because of the fuel crisis please provide as much explanation of how below - we are interested in any changes to your usual journeys or routine while at work as well as the affect these changes had on other journeys and aspects of your or your household's routine. Please indicate (if applicable) how good or bad you

found this change of experience to the journeys you make at work.

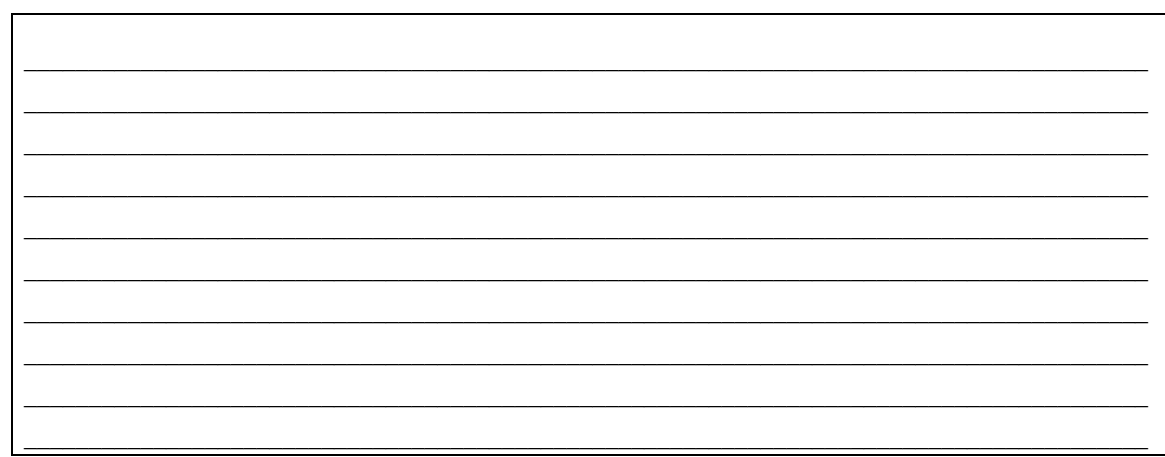

If you did make any changes to journeys undertaken at work:

Have you made such changes before in the last six months in the way you describe above (yes/no)?

Would you deal with work journeys in this way again once the fuel crisis is over (yes/no)? (please explain why or why not below). 


\section{SECTION 4 - GETTING YOUR CHILDREN TO/FROM SCHOOL OR PRE-SCHOOL}

If you do not have any children of (pre-)school age please go to Section 5.

Please give us details of how your child(ren) USUALLY get(s) to/from (pre-)school:

Who accompanies your child(ren) to/from (pre-)school (please tick the one that applies)?:
$\square$ no-one
$\square$ you
$\square$ your partner
$\square$ other (please describe)

$\square$ child(ren) unaccompanied

How do(es) your child(ren) get to/from (pre-)school (please tick more than one if, for example, the journey involves using a bus and a train):
$\square$ car
$\square$ people carrier
$\square$ bus
$\square$ walk
$\square$ cycle
$\square$ minibus $\quad \square$ taxi
$\square$ train
$\square$ other (please describe)

If a car or people carrier is used, please tick one of the following to indicate whether your child(ren):
$\square$ is/are taken alone
$\square$ is/are taken along with other parent's children
$\square$ is taken by another parent
$\square$ is/are taken in a car sharing arrangement

To the nearest mile, how far is it from your home to (pre-)school?

How many minutes does it take to get from home to (pre-)school?

If you have children that go to different (pre-)schools please indicate and explain anything not covered above:

If there were no changes to the journey to/from school on any of the days last week because of the fuel crisis please explain why below.

If you did make changes to the school journey on one or more days last week because of the fuel crisis please provide as much explanation of how below - we are interested in any changes to the usual journey as well as the affect these changes had on other journeys and other aspects of your or your household's routine. Please indicate (if applicable) how good or bad you found this change of experience in getting your child(ren) to/from school.

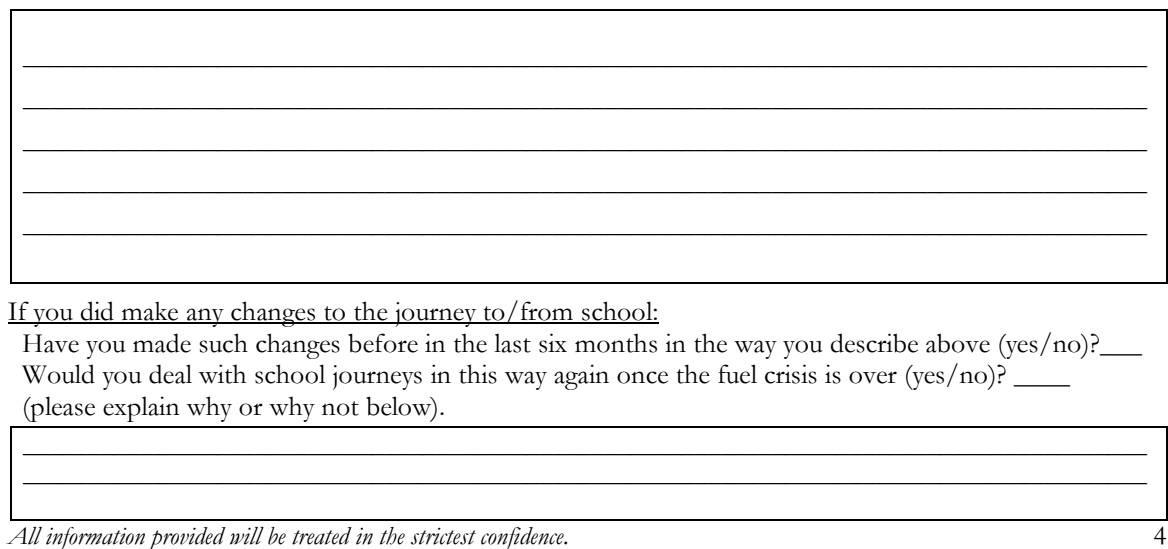




\section{SECTION 5 - GROCERY SHOPPING}

Please give us details about how you USUALLY obtain your groceries:

Which person in your household usually buys the groceries?

How often do you/they buy a large amount of groceries (three or more bags)?
$\square$ daily
$\square$ at least twice a week
$\square$ weekly
$\square$ fortnightly
$\square$ monthly
$\square$ less than once a month

How far do you/they travel to buy these (in miles):

What form(s) of transport do you/they use

How often do you/they buy a small amount of groceries (one or two bags)?
$\square$ daily
$\square$ at least twice a week
$\square$ weekly
$\square$ fortnightly
$\square$ monthly
$\square$ less than once a month

How far do you/they travel to buy these (in miles):

What form(s) of transport do you/they use

Which of the following statements is most relevant to the person who buys the groceries:

$\square$ Usually journeys made to buy groceries are only for that purpose.

$\square$ Usually buying groceries is combined with other journeys that are being make.

If your household did not change its routine of buying groceries at all last week because of the fuel crisis please explain why below.

If your household did change its routine of buying groceries because of the fuel crisis please provide as much explanation of how below - we are interested in any changes to your grocery shopping as well as the affect these changes had on other journeys and aspects of your or your household's routine. Please indicate (if applicable) how good or bad your household found this change of experience concerning grocery shopping.

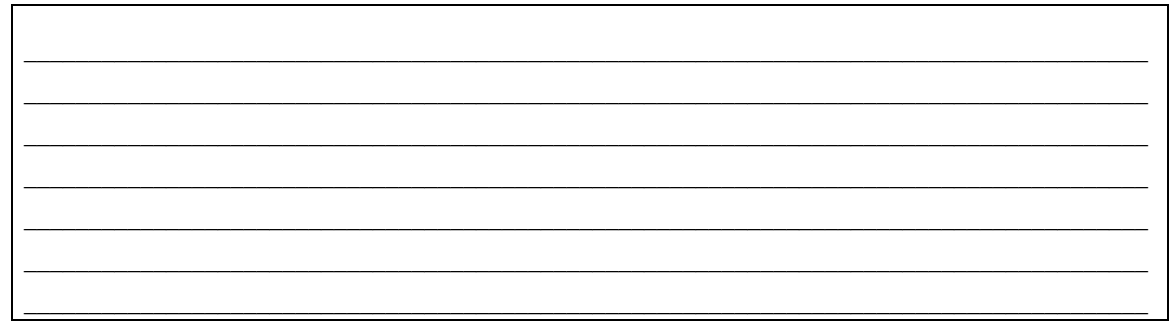

If you changed your routine of buying groceries:

Have you made such changes before in the last six months in the way you describe above (yes/no)?

Would you deal with grocery shopping in this way again once the fuel crisis is over (yes/no)? (please explain why or why not below). 


\section{SECTION 6 - OTHER CHANGES TO YOUR HOUSEHOLD ROUTINE/TRAVEL}

Please list other trips that you or your household usually makes on a regular basis that have been changed by the fuel crisis (e.g. library, pub, friends, pension, DIY, cinema, gym ...) - include purpose/frequency/ return distance (e.g. 'visit relative / weekly / 15 miles')

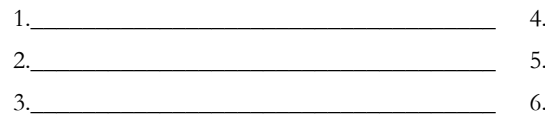

Please explain how they have been disrupted and how you have tried to cope:

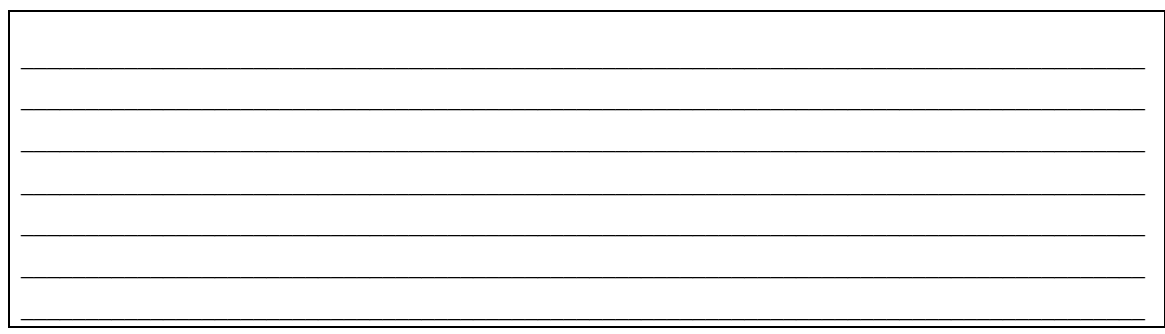

As a result of the fuel crisis did you try to combine parts of your daily/weekly routine and travel during last week (either by combining trips together that you make yourself, combining trips you make with those of other members of your household or combining trips your household makes with those of people in other households) (yes/no)?

If 'yes' please try and explain as clearly as possible how you combined trips or activities and indicate why you have not previously dealt with your daily routine in this way.

As a result of the fuel crisis did you cancel or postpone any activities or trips last week that you would normally have made (yes/no)?

If 'yes' please try and describe the activities and trips concerned including what form of transport you would have used and the consequences of cancelling them.

\begin{tabular}{ll}
\hline activities: \\
\hline consequences: \\
\\
\hline \\
All information provided will be treated in the strictest confidence.
\end{tabular}




\section{SECTION 6 - CONTINUED}

Overall, which of the following best describes the affect the fuel crisis had on you during last week (please tick one only)?

$\square$ It caused me great difficulty

$\square$ It caused me some problems but not as bad as I expected

$\square$ It caused me no problems

$\square$ I found things better than usual

Have you made greater use of the phone/Internet during the fuel crisis (yes/no)? If 'yes' please explain how and why. If 'no' please explain why not.

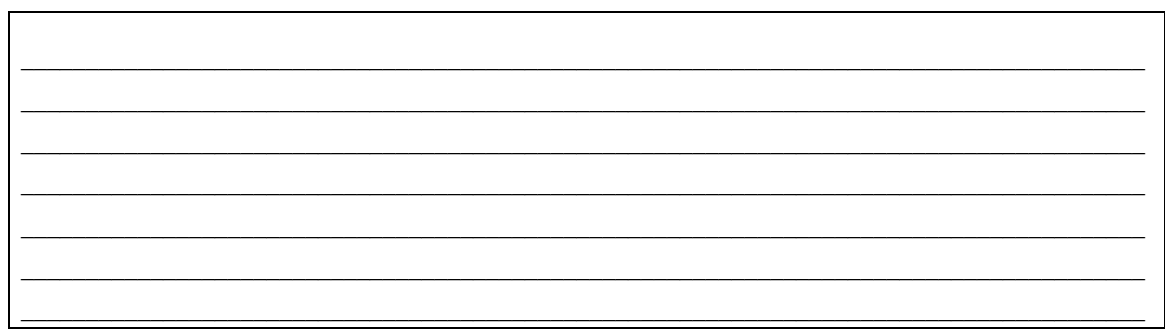

Have you sought information concerning public transport because of the fuel crisis that you would not normally have done (yes/no)?

If 'yes' please explain why and from where you sought information and if or how it helped you:

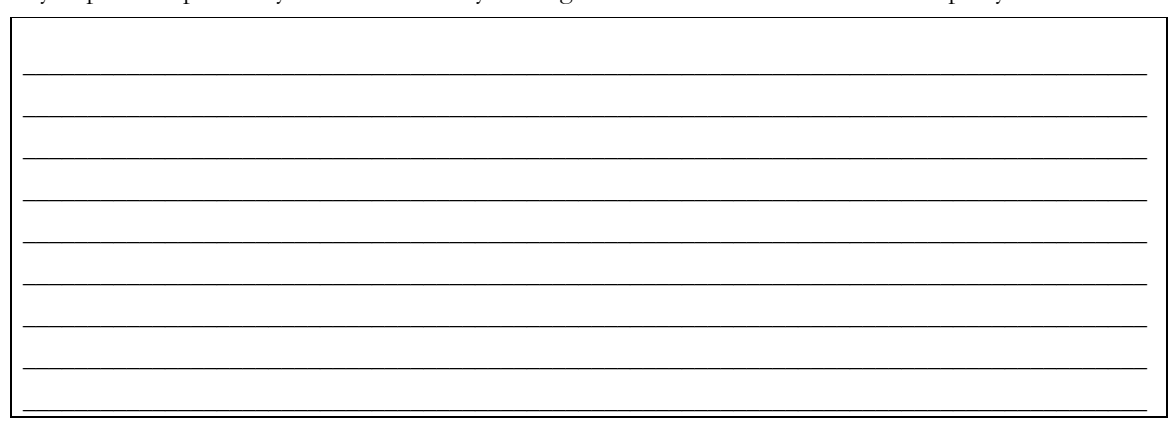

In view of your experiences last week, if on a continuous basis fuel was rationed which of the following would you be most likely to do (please tick only one):
$\square$ reduce the number of car trips you make
$\square$ buy a smaller/more fuel efficient vehicle

$\square$ move house to be nearer regular activities 


\section{SECTION 7 - YOUR VIEWS ABOUT THE FUEL CRISIS}

Please indicate to what extent you agree with the following statements:

"The fuel crisis has made me realise that I use my car more than necessary during my normal life."
$\square$ strongly agree $\quad \square$ agree
$\square$ no opinion
$\square$ disagree $\quad \square$ strongly disagree

"The air pollution has been noticeably better during the fuel crisis."
$\square$ strongly agree
$\square$ agree
$\square$ no opinion
$\square$ disagree
$\square$ strongly disagree

"I have seen less traffic during the fuel crisis."
$\square$ strongly agree
$\square$ agree
$\square$ no opinion
$\square$ disagree $\quad \square$ strongly disagree

"I found the pace of life seemed to slow down.'
$\square$ strongly agree
$\square$ agree
$\square$ no opinion
$\square$ disagree $\quad \square$ strongly disagree

"I found people were friendlier and more prepared to talk to one another."
$\square$ strongly agree
$\square$ agree
$\square$ no opinion
$\square$ disagree
$\square$ strongly disagree

"With less traffic on the roads I enjoyed driving more."
$\square$ strongly agree
$\square$ agree
$\square$ no opinion
$\square$ disagree
$\square$ strongly disagree

"I consciously drove more slowly than usual to conserve fuel."
$\square$ strongly agree
$\square$ agree
$\square$ no opinion
$\square$ disagree $\square$ strongly disagree

"If fuel duty was to be reduced, it would be fairer to charge for using roads at times of heavy traffic."
$\square$ strongly agree
$\square$ agree
$\square$ no opinion
$\square$ disagree
$\square$ strongly disagree

"I support the government in not reducing fuel taxes as a result of the crisis."
$\square$ strongly agree
$\square$ agree
$\square$ no opinion
$\square$ disagree
$\square$ strongly disagree

"The fuel crisis has made me realise that we all depend a lot more on diesel oil and petrol than I realised."
$\square$ strongly agree
$\square$ agree
$\square$ no opinion
$\square$ disagree $\square$ strongly disagree

"I believe that Government should bring in more policies aimed at cutting our dependence on diesel and petrol."
$\square$ strongly agree
$\square$ agree
$\square$ no opinion
$\square$ disagree
$\square$ strongly disagree

AND FINALLY.......P.T.O. 


\section{SECTION 8 - OTHER THINGS YOU WOULD LIKE TO SAY}

We would be very pleased to learn of any other affects the fuel crisis has had on your daily routine and travel and what you would like to see happen in the future to the levels of car use, fuel tax and related matters.

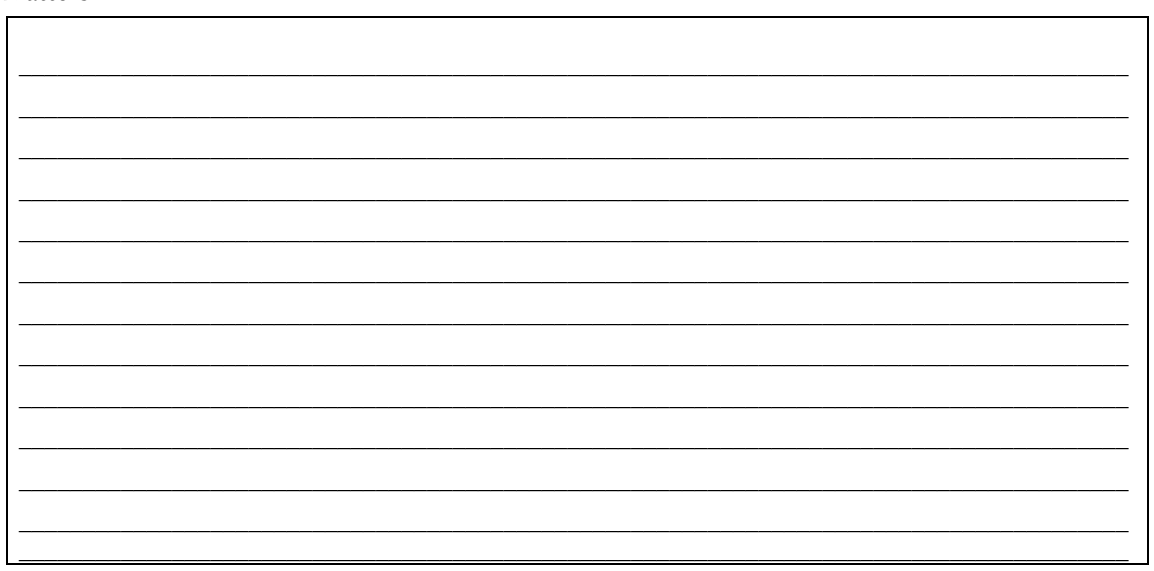

THANK YOU FOR COMPLETING THEQUESTIONNAIREAND SHARING YOUR VIEWS

If you want to be entered into the prize draw (see below) please give your name and address.

Name:

Address:

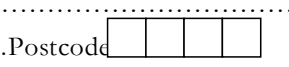

THE PRIZE DRAW

Every one who returns this form with their name and address will be entered for a prize draw to be made on 16 October 2000. The person named on the first randomly selected form will receive a cheque for ${ }_{2}^{2} 250$. (subject to terms and conditions below).

Terms \& Conditions of Draw: (1) Only those aged 18 and over on 29/09/00 will be eligible for the draw. (2) Only one entry per household. (3) All entries must reach the University of Southampton before 29 September 2000. (4) The Winner will be notified by post.

Please return you completed questionnaire (no stamp required) to:

Transportation Research Group
Dept. of Civil and Environmental Engineering
University of Southampton
FREEPOST LICENCE NO. SO 286
SOUTHAMPTON SO17 1YN


258 Transport Lessons from the Fuel Tax Protests of 2000 